\title{
Peter Marler (1928-2014)
}

\section{Pioneering interpreter of animal language.}

W hite-crowned sparrows sing in distinct dialects in different parts of California. African vervet monkeys use various alarm calls to signal different dangers, such as snakes, mammalian predators or birds of prey. Peter Robert Marler chronicled these phenomena to establish ideas about how animals communicate. He hoped to find clues about the biology of human language. How does language acquisition blend innate knowledge and learning?

Marler, who died on 5 July, first became interested in animal sounds as a doctoral student in botany at University College London. Surveying potential nature reserves in Scotland, UK, he noticed that the song of the chaffinch Fringilla coelebs changed from valley to valley. This led to a second $\mathrm{PhD}$, in zoology from the University of Cambridge, UK, in 1954, for which he described the complete vocal repertoire of this songbird, revealing that different chaffinch calls signalled different dangers. The observation was unprecedented.

Born in 1928 in Slough, near London, Marler left England in 1957 to join the faculty of the University of California, Berkeley. It was the heyday of ethology, the study of the behaviour of animals in their natural settings. Pioneered in Europe by Konrad Lorenz, Nikolaas Tinbergen and Karl von Frisch, ethology differed from work of comparative psychologists in the United States such as B. F. Skinner, who preferred to study animals - mostly rats and pigeons - in simplified laboratory settings. Whereas the psychologists sought universal rules of learning that applied to all animals, ethologists sought to understand animals' adaptations.

Marler, a field biologist, taught his students to imagine the challenges faced by wild animals, the resources and threats they encountered, the bonds they had to build, and the information they sought and conveyed. He challenged us to identify what signals they used in which contexts, and what responses they elicited. The song of a territorial chaffinch was a loud and ringing threat to rivals, but when the same male courted a female at close quarters, his voice morphed into a jumble of soft sounds reminiscent of the sweet talk of lovers. Notice these things, Marler taught us, but be careful with the inferences you draw.

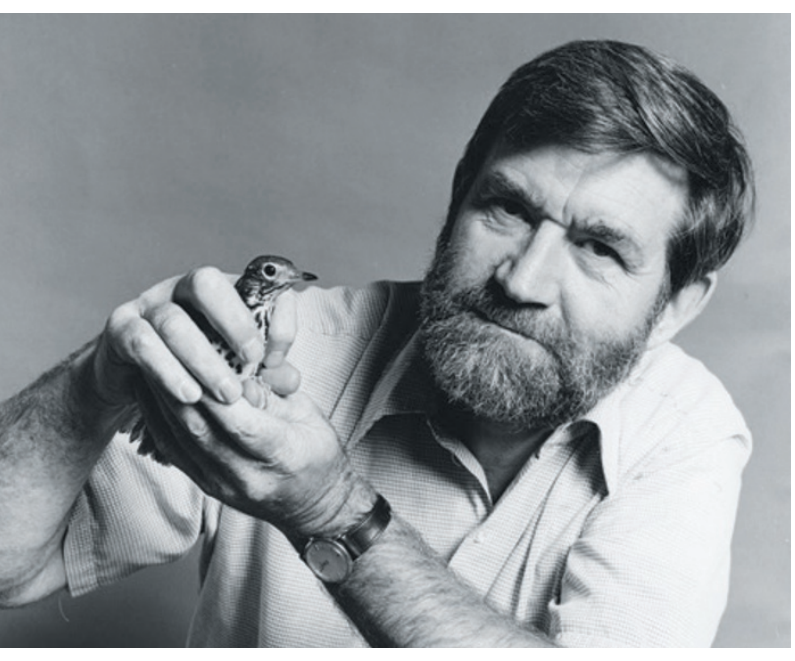

to Japan to study macaques. Marler himself spent time studying colobus monkeys in Uganda and then, with primatologist Jane Goodall, the social behaviour of chimpanzees in Tanzania. He had hoped to glean insights on human language. He learned much about the signals that chimpanzees use, but felt that human language remained in its own class.

Marler astutely realized that if he shifted his focus from language to vocal learning, then birds had much to offer. Early on, he noticed that songbirds were picky about what sounds they imitated, and that choice often occurred during the first year of life. Moreover, the stages of vocal learning were set. This explained why

I was enthralled when I first heard Marler lecture at Berkeley. Here was a young Charles Darwin building a rational edifice to understand how animals communicate. The goal was to discover how much of this process was instinctual, how much was learned and how had it all evolved.

Marler was superb at designing laboratory and field experiments. He used the latest techniques to record, analyse and play back sounds so that observers and instruments participated in 'conversations' with animals. After quantifying animals' responses, Marler would write his report, and there emerged his signature style. Taken together, he would say, "the observations suggested" some interpretation. It was his way of inviting readers and colleagues to join him in his exploration. No ringing truth, no strident dogma - it left him ample room to lead with ideas and observations while keeping the intellectual framework flexible.

Marler moved from Berkeley to Rockefeller University in New York in 1966, and in 1972 became the first director of the university's Center for Field Research in Ecology and Ethology in Millbrook, north of Manhattan. In this unique facility, he fostered the integration of field and laboratory work. In 1989, he moved his laboratory to the University of California, Davis, where he worked as a professor until retiring in 1994.

Marler encouraged his students to study any species that took their fancy: birds, flies, tarantulas, lizards, electric fish, bats, cetaceans, gerbils and wolves, among others. Students went to Kenya to study vervet monkeys, to Borneo to study orang-utans, and the dialects of his chaffinches disappeared when the young birds were reared away from wild-type models. Moreover, the what, when and how of vocal learning were directed, as if by an innate schoolteacher. Marler suggested that this interlocking of nature and nurture acted as an 'instinct to learn'.

This important insight was an alternative to the learning by trial and reward favoured by comparative psychologists. When it came to learning language, Marler felt that humans were more like his songbirds than like Skinner's rats - a conclusion that had repercussions. If language acquisition, so central to our manner of thinking, is ruled by biological predisposition, what does this tell us about the nature of human knowledge? Is it as idiosyncratic as the dialect of a chaffinch? At a time when much of the buzz in biology was molecular, Marler was one of the few philosophers of nature.

Peter was a gentleman. He adored his wife Judith and their three children. For many years, she ran the encampments where Peter and his students went to collect nesting songbirds, and she established home nurseries for hand-rearing the young. Peter and Judith were extraordinarily gracious hosts. They loved good food, good booze, good conversation and a good party. It was the good luck of Marler's students to be part of that world..

Fernando Nottebohm is professor of animal behaviour at Rockefeller University in New York, USA. He earned his PhD under Peter Marler at the University of California, Berkeley, in the 1960s.

e-mail:nottebo@mail.rockefeller.edu 